\title{
Role of Vascular Endothelial Growth Factor and Angiopoietin 1 in Renal Injury in Hemolytic Uremic Syndrome
}

\author{
Shinichiro Ohara Yukihiko Kawasaki Yusaku Abe Masahiro Watanabe \\ Atsushi Ono Kazuhide Suyama Koichi Hashimoto Takashi Honda \\ Junzo Suzuki Mitsuaki Hosoya \\ Department of Pediatrics, Fukushima Medical University School of Medicine, Fukushima, Japan
}

\section{Key Words}

Vascular endothelial growth factor • Angiopoietin 1 •

Hemolytic uremic syndrome

\begin{abstract}
Background/Aims: The recovery process from renal injury in hemolytic uremic syndrome (HUS) remains obscure. In order to clarify the role of vascular endothelial growth factor (VEGF) and angiopoietin 1 (Ang-1) in the renal recovery from HUS, we produced a model of mild HUS and examined the renal recovery process. Methods: We investigated three groups of mice. Group 1 consisted of mice that received an injection of Shiga toxin 2 (Stx2) and lipopolysaccharide (LPS); group 2 consisted of mice that received an injection of low dose of Stx 2 and LPS, and group 3 consisted of control mice. Results: Serum Cr levels in group 1 were greater than those in group 2, and all mice in group 1 died, whereas all mice in group 2 remained alive. Endothelial injury at $24 \mathrm{~h}$ in group 1 was higher than in group 2. Electron-microscopic findings demonstrated that the endothelial cells formed immature capillary-like lumina from 7 to 28 days with increases in the expression of CD31-positive cells. Glomerular VEGF expression decreased at $72 \mathrm{~h}$ in group 1, but gradually increased in group 2. Glomerular Ang-1 expression peaked from $72 \mathrm{~h}$
\end{abstract}

to 28 days. Ang-1 expression was frequently found in the endothelial cell region of vesicle walls simultaneous with increased CD31-positive staining. Conclusion: Our findings suggest that VEGF and Ang-1 play important roles in the recovery process, particularly in the regeneration of endothelial injury.

Copyright $\odot 2012$ S. Karger AG, Basel

\section{Introduction}

Hemolytic uremic syndrome (HUS) defined as a triad of microangiopathic hemolytic anemia, thrombocytopenia, and acute renal failure is typical of renal disease with endothelial cell dysfunction, and electron microscopy (EM) examination shows endothelial swelling and detachment from the basement membrane [1-4].

The cause is mainly Shiga toxin (Stx)-producing Escherichia coli infection in most infant cases, and it is the most common cause of acute renal failure in children $[2,3]$.

HUS mortality is reported to be between 3 and 5\%, and deaths due to HUS are nearly always associated with severe extrarenal disease, including central nervous system involvement. Approximately two thirds of children

\section{KARGER}

Fax +4161306 1234 E-Mail karger@karger.ch www.karger.com
(C) 2012 S. Karger AG, Basel

0250-8095/12/0366-0516\$38.00/0

Accessible online at:

www.karger.com/ajn
Yukihiko Kawasaki

Department of Pediatrics

Fukushima Medical University School of Medicine

1 Hikariga-oka, Fukushima City, Fukushima 960-1295 (Japan)

E-Mailkyuki@fmu.ac.jp 
with HUS require dialysis therapy, and about one third have milder renal involvement without the need for dialysis therapy. Most HUS patients recover from renal injury with the help of supportive treatment; however, the recovery process from renal injury remains obscure [1-4].

On the other hand, with regard to vascular recanalization, there have been some reports on revascularization factor including vascular endothelial growth factor (VEGF) and angiopoietin 1 (Ang-1) in the recovery phase of renal injury [5-10]. VEGF is one of the most important and potent angiogenic factors activating endothelial cells, and subsequent, vascular neoformation. Ang constitutes a family of secreted growth factors that predominantly target the endothelia. Ang-1 binds to and phosphorylates the Tie- 2 receptor, with context-dependent effects including the enhancement of endothelial cell survival, and capillary stabilization and sprouting [10-12]. There have been few reports on the association between VEGF and Ang-1 in renal recovery from acute renal injury to date, and this recovery process remains obscure [9].

HUS mice models have been used for the examination of HUS pathogenesis. It has been reported that C57BL/6 mice treated with the intraperitoneal co-injection of purified Stx2 plus lipopolysaccharide (LPS) afford a complete model of HUS, including thrombocytopenia, hemolytic anemia, and renal failure [13-17].

In order to clarify the role of VEGF and Ang-1 in the renal recovery from HUS, we produced a mouse model of mild HUS and examined the renal recovery process in mice with HUS as well as the relationship between their renal recovery and VEGF and Ang-1.

\section{Methods}

\section{Disease Model}

Animal experiments were performed using 5-week-old male inbred C57BL/6 mice (Japan SLC, Inc., Shizuoka, Japan). Mice were allowed free access to normal mice chow and tap water. All animal experiments were performed according to the Institutional Animal Care and Use Committee guidelines of Fukushima Medical University School of Medicine (FMUSM).

\section{Stx and LPS}

Stx 2 was produced in E. coli DH5 using the pLPSH3 plasmid and purified by immunoaffinity chromatography. LPS (O55:B5), purified by gel filtration chromatography and gamma irradiation, was purchased from Sigma-Aldrich (St. Louis, Mo., USA).

\section{Experimental Protocol}

One hundred and twenty mice were divided into three groups. Group 1 consisted of mice that received an intraperitoneal injec- tion of a lethal dose of Stx2 (225 ng/kg) and LPS $(300 \mu \mathrm{g} / \mathrm{kg})$. Group 2 consisted of mice that received an intraperitoneal injection of a low sublethal dose of Stx2 (100 ng/kg) and LPS (100 $\mu \mathrm{g} /$ $\mathrm{kg}$ ). Mice in the control group (group 3) were inoculated with saline. Five mice from each group were sacrificed at 6, 12, 24, $72 \mathrm{~h}$, or at 7, 14, 28 days after administration under chloroform anesthesia.

After cardiac puncture for blood sampling, the kidneys were removed, weighed, cut into portions, and used for assessment by light microscopy (LM), immunohistochemical microscopy (IHM), and EM.

\section{Laboratory Investigation}

All blood analysis was performed by FMUSM Laboratories. Mice were euthanized, and blood was collected. Whole blood for cell count analysis was collected in hematology tubes containing tripotassium EDTA. In addition, total blood was left to coagulate at room temperature for $10 \mathrm{~min}$, after which samples were centrifuged at 3,000 rpm and $4^{\circ} \mathrm{C}$ for $10 \mathrm{~min}$, and serum was collected. Biochemical determinations of serum creatinine levels were performed.

\section{Histological Examination}

LM, IHM and EM

The renal tissue was fixed in buffered formalin and embedded in paraffin for LM examination. Sections (2-3 $\mu \mathrm{m}$ thick) were then individually stained with hematoxylin-eosin, periodic acidSchiff, and periodic acid-silver methenamine, and observed under a light microscope. Three observers semiquantitatively graded extracellular matrix accumulation in each quadrant in 20 glomeruli per kidney on a scale from 0 to 3 as follows. Endothelial injury score: 0 = absence of mesangiolysis; $1=$ mesangial area (MA) exhibiting slight lucency ( $0-25 \%$ disruption of mesangial cell); 2 = MA exhibiting moderate lucency (25-50\% disruption of mesangial cell) with preservation of the underlying glomerular tuft architecture, and $3=$ MA exhibiting marked lucency (50$100 \%)$ with degeneration and disruption of mesangial cell, usually in association with microaneurysm formation. Mesangial cell proliferation score: $0=$ absence of mesangial cell proliferation; 1 = slight increase in mesangial cells; 2 = moderate increase mesangial cells; 3 = marked increase in mesangial cells.

The immunoperoxidase staining for $\alpha$-SMA, PCNA, VEGF, Ang-1, and CD31 was evaluated using the methods previously described by Kawasaki et al. [18, 19]. Primary antibodies included mouse anti-human $\alpha$-SMA (1A4; Dako, Glostrup, Denmark), mouse anti-human PCNA (19A2; Coulter, Hialeah, Fla., USA), goat anti-mouse VEGF (RM0008-6572; NOV) monoclonal antibodies, rabbit anti-mouse Ang-1 (Anti-AUGPT1; LSB), and rabbit anti-mouse CD31 (ER-MP12; BMA) polyclonal antibodies were used for IHM.

RNA Extraction and Measurement of Each DNA by PCR

Total cell RNA was extracted from the isolated of homogenized renal cortex in a modified guanidine thiocyanate buffer by an acid phenol-chloroform extraction method. The extracted RNA was reverse transcribed before PCR amplification of sequences specific for VEGF and Ang-1. Taqman PCR for VEGF and Ang-1 was performed according to the protocol supplied by the manufacturer. The thermal cycler conditions were as follows: incubation for $10 \mathrm{~s}$ at $95^{\circ} \mathrm{C}$ was followed by 5 -second denaturation 


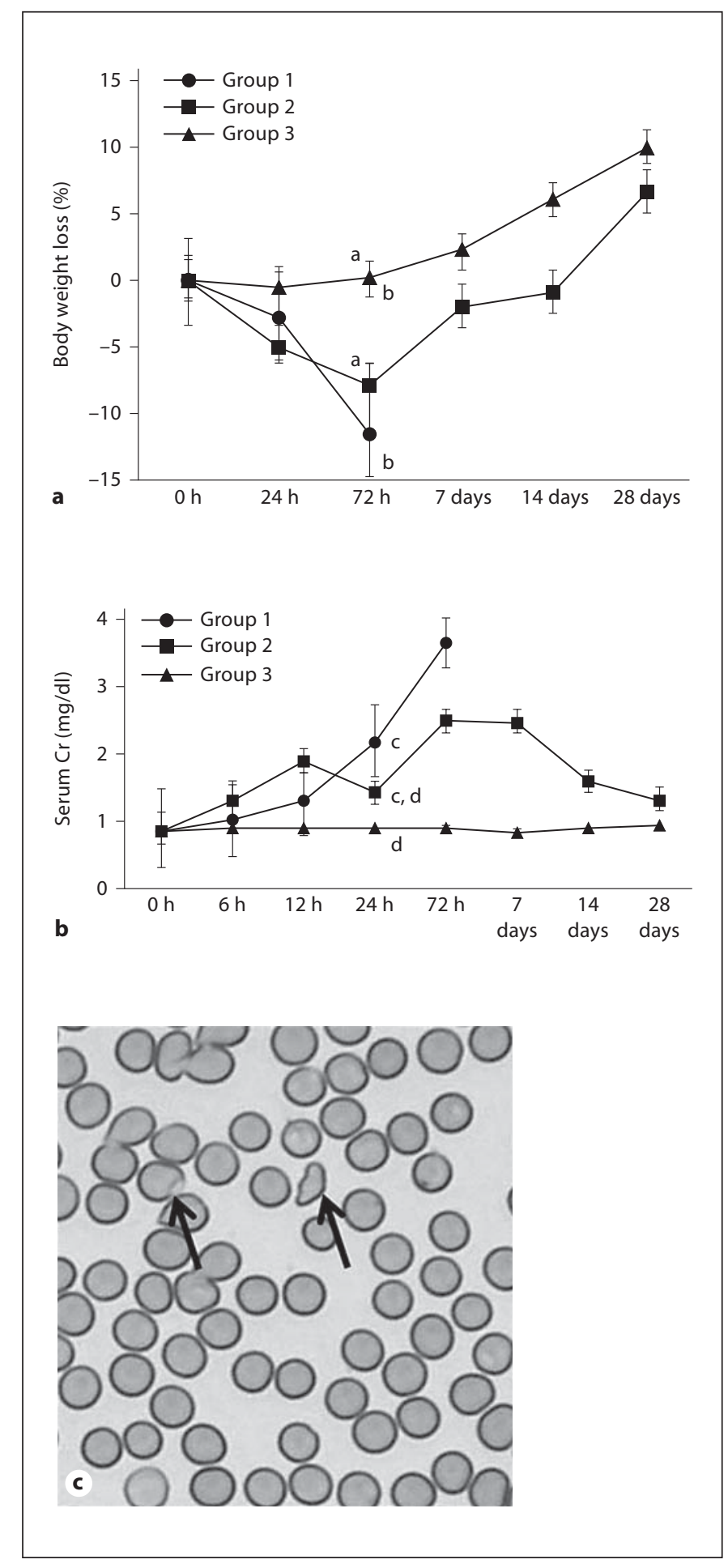

Fig. 1. Intergroup comparison of the ratio of body weight loss and serum creatinine levels. a Comparison of the ratio of body weight loss among groups. a vs. b: $\mathrm{p}<0.01$. b Serum creatinine levels in groups 1 and 2 were higher than those in group 3, and serum creatinine levels in group 1 were higher than those in group 2. c vs. d: $p<0.01$. c Fragmented erythrocytes (arrows) were found in the peripheral blood at $6 \mathrm{~h}$ in mice from group 1 . at $95^{\circ} \mathrm{C}$ and extension for $31 \mathrm{~s}$ at $60^{\circ} \mathrm{C}$ per cycle using an $\mathrm{ABI}$ Prism 7300 Sequence Detection System. The real-time PCR data were analyzed using the standard curve method or the delta-delta $\mathrm{Ct}$ method. The standard curve for each GAPDH gene in the glomerular cells was checked. The identity of the PCR products was confirmed by forward and reverse sequence analysis.

\section{Statistics}

Values are expressed as mean \pm SD. Statistical analysis was performed on a Macintosh computer with a software package for statistical analysis (Stat View, Abacus Concepts, Berkeley, Calif., USA). Differences in laboratory data among groups were assessed by the Mann-Whitney rank-sum test or Wilcoxon signed-rank test or contingency tables $\left(\chi^{2}\right)$. Correlations were evaluated using Fisher's $r$ test. A p value of $<0.05$ was considered significant.

\section{Results}

\section{Intergroup Comparison of Body Weight and Renal Findings}

Ratios of body weight loss in the three groups are shown in figure 1a. The ratios of body weight loss in group 1 and group 2 were higher than that in group 3 at $72 \mathrm{~h}(12.0 \pm 2.0$ vs. $2.1 \pm 0.7 \%, \mathrm{p}<0.01$, and $8.1 \pm 1.3$ vs. $2.1 \pm 0.7 \%, p<0.01$, respectively). The ratio of body weight loss at $72 \mathrm{~h}$ in group 1 was higher than that in group $2(12.0 \pm 2.0$ vs. $8.1 \pm 1.3 \%, \mathrm{p}<0.01)$. Ratios of body weight loss subsequently decreased. However, body weights at 4 weeks after injection were higher than those prior to injection. Fragmented erythrocytes were found in mice from groups 1 and 2 at $6 \mathrm{~h}$ after the administration of Stx 2 and LPS (fig. 1c). Serum creatinine levels (mg/ dl) in three groups are shown in figure $1 b$. Serum creatinine levels at $24 \mathrm{~h}$ after the administration of Stx2 and LPS in group 1 and group 2 were higher than in group 3 $(2.2 \pm 0.3$ vs. $0.9 \pm 0.2 \%, \mathrm{p}<0.01$, and $1.5 \pm 0.3$ vs. 0.9 $\pm 0.2 \%, \mathrm{p}<0.05$, respectively). Serum creatinine at $72 \mathrm{~h}$ after the administration of Stx 2 and LPS in group 1 was also higher than that in group $2(3.8 \pm 0.5$ vs. $2.5 \pm 0.4 \%$, $\mathrm{p}<0.01)$. All mice in group 1 subsequently died, and the serum creatinine levels in group 2 peaked from $72 \mathrm{~h}$ to 7 days after administration and then decreased from 14 days after administration.

\section{Intergroup Comparison of Pathological Findings with \\ Time after the Administration of Stx 2 and LPS \\ LM Findings \\ Endothelial injury scores in the three groups are} shown in figure 2a. Endothelial injury scores at $6 \mathrm{~h}$ in group 1 and group 2 were higher than those in group 3 . There were no significant differences in endothelial in- 

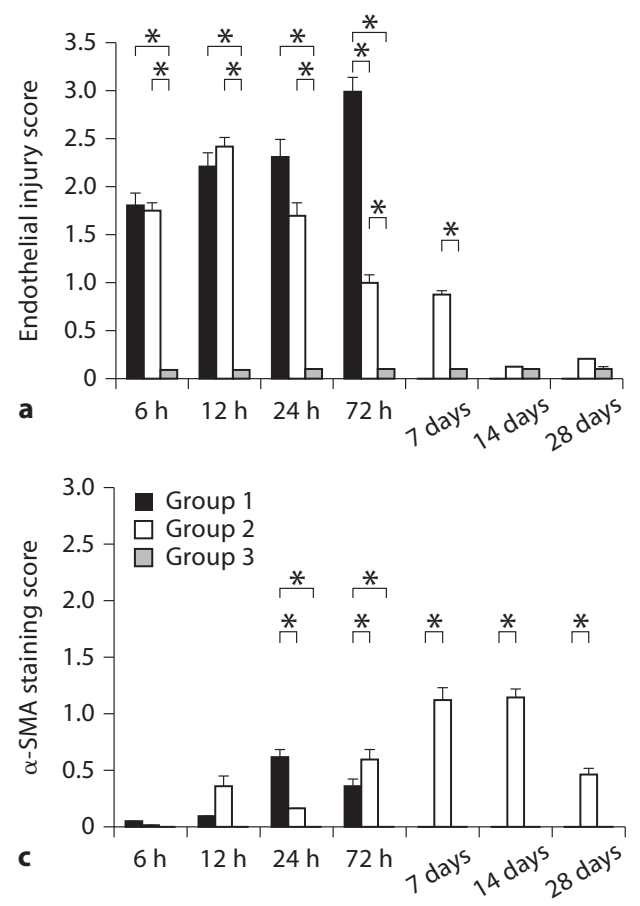
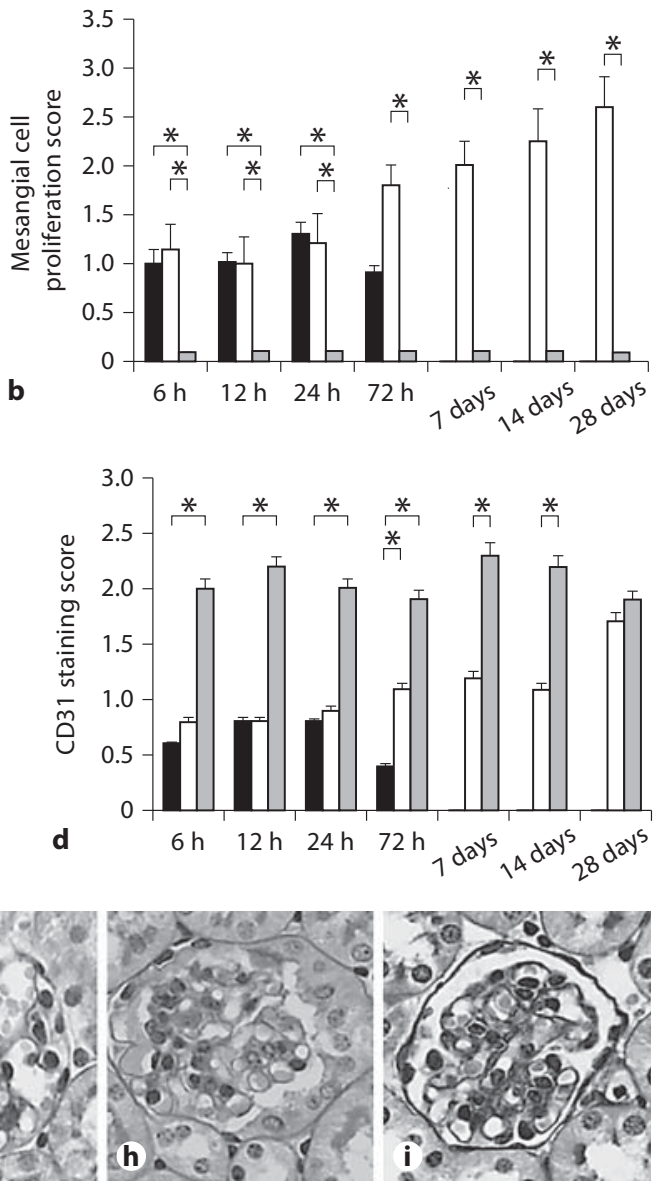

Fig. 2. Intergroup comparison of the pathological findings. ${ }^{*} \mathrm{p}<$ 0.01. a Endothelial injury scores among groups. b Mesangial cell proliferation scores among groups. c Glomerular $\alpha$-SMA staining scores among groups. d Glomerular CD31 staining scores among groups. e Endothelial cell injury, cystic dilatation of the glomerular tuft (single arrow) and mesangiolysis (double arrows) observed at $6 \mathrm{~h}$ after the administration of Stx 2 and LPS in group 1 (LM finding). Periodic acid-Schiff (PAS). $\times 400$. f Severe mesangiolysis and cystic dilatation of the glomerular tuft were observed, but no mesangial cell proliferation or increase in mesangial matrices was observed at $72 \mathrm{~h}$ after the administration of Stx 2 and LPS in group
1 (LM finding). PAS. $\times 400 . \mathbf{g}$ Mild mesangiolysis and cystic dilatation of glomerular tuft were observed at $6 \mathrm{~h}$ after the administration of Stx 2 and LPS in group 2 (LM finding). PAS. $\times 400$. h Mesangiolysis and cystic dilatation of the glomerular tuft did not progress, and proliferation of mesangial cells was observed at 7 days after the administration of Stx 2 and LPS in group 2 (LM finding). PAS. $\times 400$. i Mesangiolysis and cystic dilatation were improved, and reformation of the glomerular tuft was commonly observed at 28 days after the administration of Stx 2 and LPS in group 2 (LM finding). PAS. $\times 400$. jury scores at 6 and $12 \mathrm{~h}$ between groups 1 and 2, but endothelial injury scores at 24 and $72 \mathrm{~h}$ were higher in group 1 than in group 2. Endothelial injury scores in group 2 gradually decreased after $72 \mathrm{~h}$. Mesangial cell proliferation scores in the three groups are shown in figure $2 \mathrm{~b}$. Mesangial cell proliferation scores from 6 to $24 \mathrm{~h}$ in group
1 and group 2 were higher than those in group 3. There was no significant difference in mesangial cell proliferation scores at $24 \mathrm{~h}$ between groups 1 and 2 , but the mesangial cell proliferation score at $72 \mathrm{~h}$ in group 1 was decreased and that in group 2 gradually increased to peak at 28 days. 
Fig. 3. Changes in EM findings after the administration of Stx 2 and LPS in groups 1 and 2. a Severe mesangiolysis, degeneration of endothelial cells, cystic dilatation of the glomerular tuft and abnormal hemocoagulation were found at $72 \mathrm{~h}$ after the administration of Stx 2 and LPS in group 1. $\times 3,000$. $\mathbf{b}$ Cystic dilatation of the glomerular tuft and mesangial cell proliferation were still observed together with residual endothelial cell proliferation at 7 days after the administration of Stx 2 and LPS in group 2. $\times 3,000$. c Elongated cytoplasmic processes of the endothelial cells formed immature capillary-like lumina (arrow) at 7 days after the administration of Stx 2 and LPS in group 2. $\times 6,000$. d Proliferation of mesangial cells and an increase in mesangial matrices were found at 28 days after the administration of Stx 2 and LPS in group 2. $\times 3,000$.

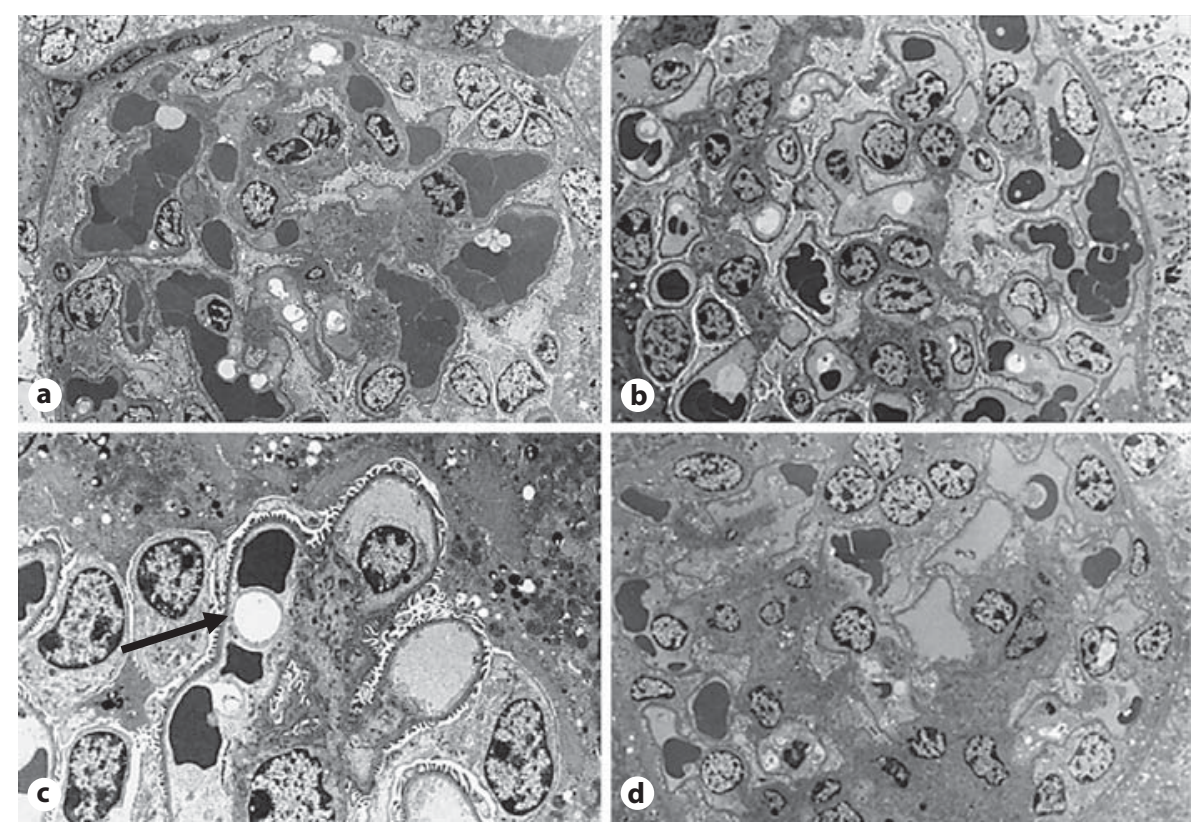

Intergroup Comparison of EM Findings

Endothelial cell injury and mesangiolysis were apparent in group 1 and group 2 from 6 to $72 \mathrm{~h}$. In group 1, severe mesangiolysis, degeneration of endothelial cells and cystic dilatation of the glomerular tuft, presence of a fibrin-like substance, and abnormal hemocoagulation were found at $72 \mathrm{~h}$ after administration of Stx 2 and LPS (fig. 3a).

In group 2, cystic dilatation of the glomerular tuft was observed together with residual endothelial cell proliferation and elongation of endothelial cell processes. Endothelial cells were found to form immature capillary-like lumina from 7 to 28 days after administration (fig. 3b, c). Subsequently, mesangial cell proliferation was found at 28 days after administration (fig. $3 \mathrm{~d}$ ).

\section{Immunohistopathological Findings}

$\alpha$-SMA staining scores are shown in figure $2 \mathrm{c}$. There was no significant difference in scores at $12 \mathrm{~h}$ between groups 1 and 2, but the scores at $72 \mathrm{~h}$ in group 1 was decreased, while that in group 2 gradually increased to peak at 14 days.

Glomerular CD31 staining scores are shown in figure 2d. Glomerular CD31 staining scores from 6 to $24 \mathrm{~h}$ in group 1 and group 2 were decreased; however, the glomerular CD31 staining scores in group 2 increased at $72 \mathrm{~h}$ and subsequently peaked at 28 days.
Glomerular VEGF expression is shown in figure $4 \mathrm{a}-\mathrm{d}$. Glomerular VEGF expression at 6 and $24 \mathrm{~h}$ in group 1 and group 2 was greater than that in group 3 . There were no differences in expression levels between groups 1 and 2 , but glomerular VEGF expression at $72 \mathrm{~h}$ in group 1 was decreased, whereas that in group 2 gradually increased to peak from $72 \mathrm{~h}$ to 7 days. Higher RNA doses of VEGF in total cells were detected by RT-PCR from $72 \mathrm{~h}$ to 7 days in comparison to those at $6 \mathrm{~h}$.

Glomerular Ang-1 expression is shown in figure 4e-h. Glomerular slight Ang-1 expression at 6 and $24 \mathrm{~h}$ was detected in the glomeruli in all groups, and significant Ang1 expression was observed from $72 \mathrm{~h}$ in group 2, peaking from 7 to 28 days, and these expression levels were higher than those in groups 1 and 3. RNA doses of Ang-1 levels in total cells detected by RT-PCR from $72 \mathrm{~h}$ to 28 days in group 2 were higher than at $6 \mathrm{~h}$.

\section{Discussion}

Body weight loss and increases in serum Cr levels were greater in severe HUS model mice induced by high LPS and Stx 2 than in mild HUS model mice induced by low LPS and Stx. All severe HUS model mice died at 80-90 h, and all mild HUS model mice survived. Endothelial injury and mesangiolysis scores at $24 \mathrm{~h}$ in severe HUS model mice were higher than those in mild HUS model mice. 
Fig. 4. Glomerular VEGF and Ang-1 staining and a comparison of VEGF and Ang-1 staining scores in the glomeruli. ${ }^{*} \mathrm{p}<0.01$. a Glomerular VEGF staining scores among groups. b Glomerular VEGF staining was observed in the glomerular tuft (arrows) at $24 \mathrm{~h}$ in group $1 . \times 400$. c RNA doses of VEGF in total cell detected by RTPCR at $6 \mathrm{~h}$ were higher than those at 12, 24,48 , and $72 \mathrm{~h}$ in group 1 . d RNA doses of VEGF in total cell detected by RT-PCR from $72 \mathrm{~h}$ to 7 days were higher than those at $6 \mathrm{~h}$ in group 2. e Glomerular Ang-1 staining scores among groups. f Glomerular Ang-1 staining was observed in the glomerular tuft (arrows) at $14 \mathrm{~h}$ in group 2 . $\times 400$. $\mathbf{g}$ RNA doses of Ang-1 in total cell were detected by RT-PCR from 6 to $12 \mathrm{~h}$ in group 1. h RNA doses of Ang-1 in total cell detected by RT-PCR from 72 h to 28 days were higher than those at $6 \mathrm{~h}$ in group 2 .
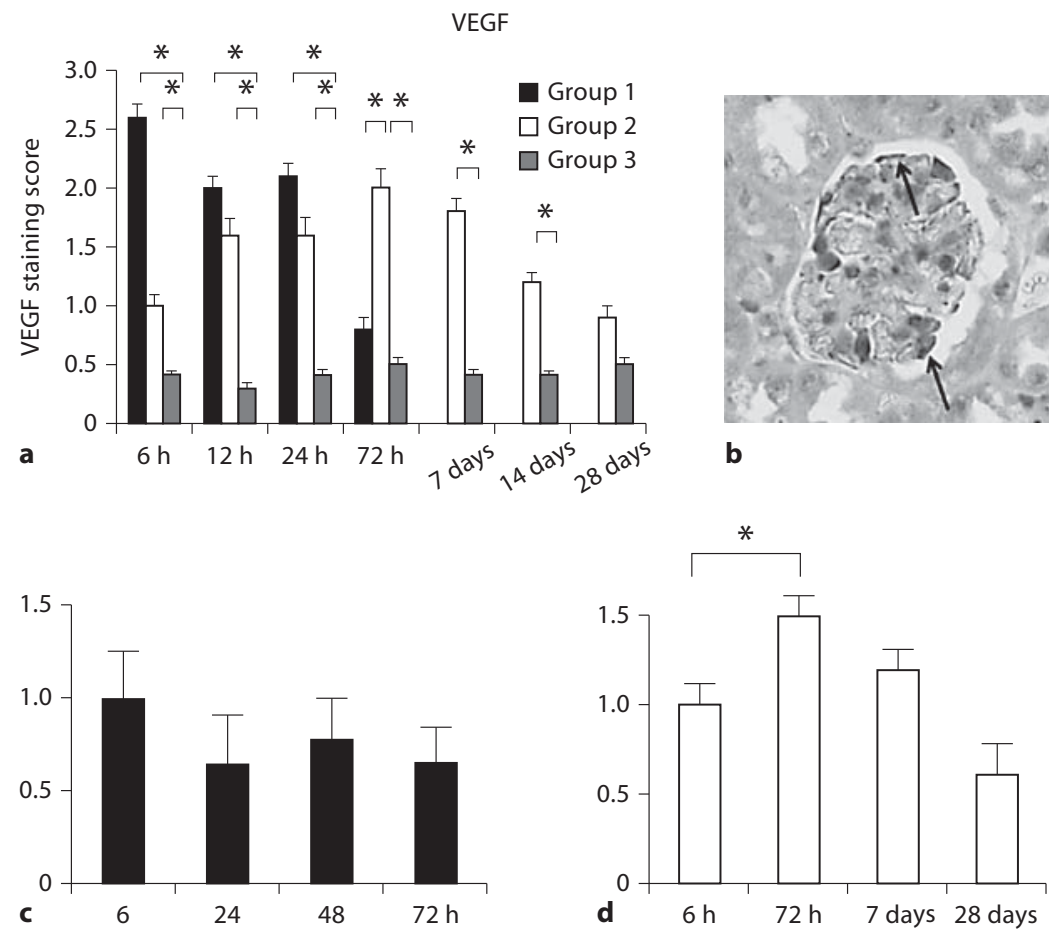

Ang-1
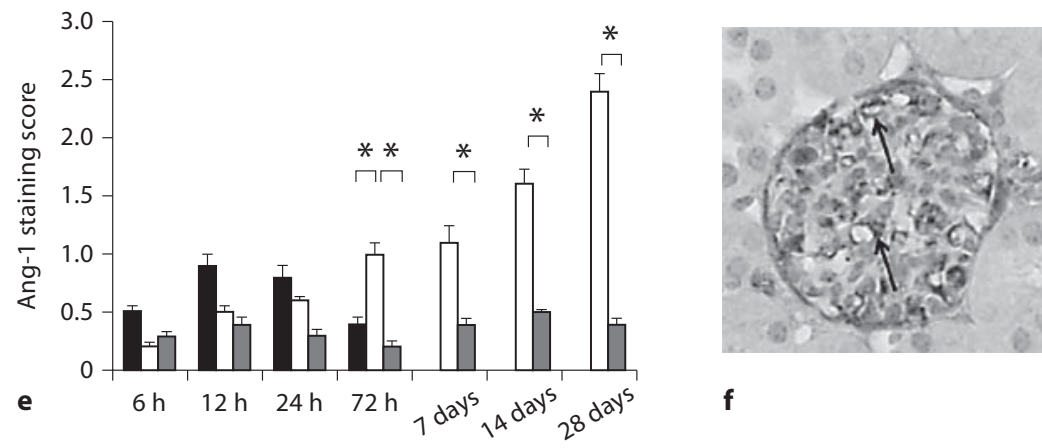

f
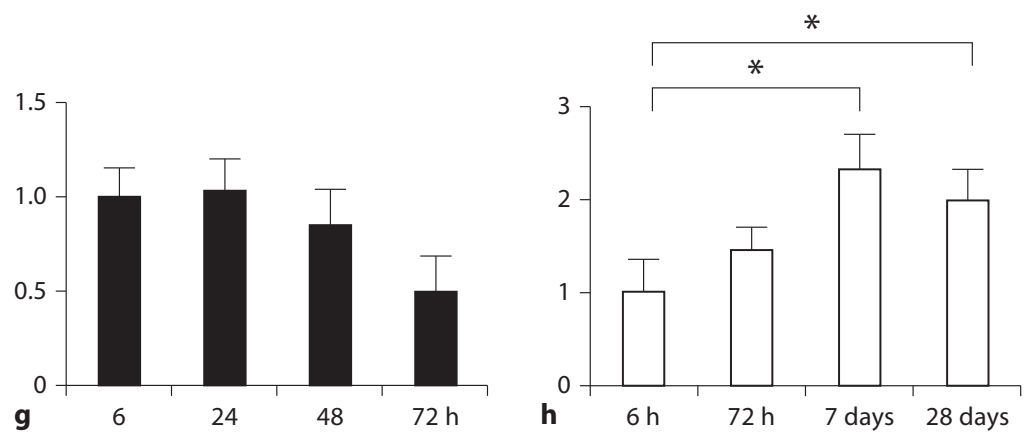
In addition, endothelial cell injury was decreased from 7 days, and mesangial proliferation scores and CD31-positive expression were increased from 7 to 28 days in mild HUS model mice. EM findings revealed that the endothelial cells formed immature capillary-like lumina from 7 to 28 days simultaneous with an increase in the expression of CD31-positive cells. Furthermore, glomerular VEGF and Ang-1 expression in mild HUS model mice gradually increased to peak from $72 \mathrm{~h}$ to 7 days, and the total cell RNA doses of VEGF and Ang-1 detected by RTPCR at these time points were higher than those at $6 \mathrm{~h}$.

As to the HUS animal model, there have been some reports on HUS animal models to date; however, none has satisfactorily investigated the full pathophysiology of HUS [13-17]. Keepers et al. [17] established that C57BL/6 mice treated with LPS and Stx 2 afford a complete model of HUS that includes thrombocytopenia, hemolytic ane$\mathrm{mia}$, and renal failure that define the disease in humans. This mouse model is useful for the identification of therapeutic targets and the development of new treatments for HUS. However, C57BL/6 mice treated with LPS and Stx 2 are not adequate for the evaluation of the recovery process from HUS-induced renal failure as this mouse died at 3-4 days. Thus, we made a mild HUS model through treatment with a low sublethal dose of Stx2 (100 $\mathrm{ng} / \mathrm{kg})$ and LPS $(100 \mu \mathrm{g} / \mathrm{kg})$. These mild HUS model mice showed the same thrombocytopenia, hemolytic anemia, and renal failure that define the disease in humans while surviving the administration of LPS and Stx2, enabling us to observe the recovery process from renal injury. This mild HUS mouse affords an adequate model for investigation of the recovery process from acute renal injury, including glomerular endothelial dysfunction.

As to the recovery phase of renal injury, Zhang et al. [20] reported a relationship between mesangial cells and endothelial cells in the remodeling of glomerular capillary loops in a rat model of anti-Thy- 1 antibody-induced glomerulonephritis and found that type I and type III collagen produced by the transformed mesangial cells may enhance endothelial cell proliferation and capillary remodeling in Thy-1-induced nephritis. In our mild HUS model, at $24 \mathrm{~h}$ after the administration of LPS and Stx2, endothelial injury and mesangiolysis were found, and CD31-positive cell numbers were decreased. The numbers of $\alpha$-SMA-positive and CD31-positive cells subsequently increased at $72 \mathrm{~h}$ after the administration of LPS and Stx 2 and peaked from 14 to 28 days. EM findings revealed that the endothelial cells formed immature capillary-like lumina from 7 to 28 days simultaneous with an increase in the expression of CD31-positive cells. Thus, it appears that $\alpha$-SMA-positive cells and CD31-positive cells may be associated with the renal recovery process.

On the other hand, VEGF is one of the most important and potent angiogenic factors activating endothelial cells and subsequent vascular neoformation [5-9]. Recently, Ostendorf et al. [7] showed that VEGF mediates endothelial cell survival and glomerular capillary repair in several models of rat glomerulonephritis. For example, inhibition of VEGF by a specific inhibitor led to more severe glomerular damage in the anti-Thy 1.1 glomerulonephritis rat model. Haas et al. [8] reported that glomerular VEGF mRNA expression increased on day 3 and returned back to the baseline level and below at day 14 when the glomerular recovery process was completed. In our study, glomerular VEGF expression was found to be higher in the mild HUS model mice undergoing the regeneration processes than in typical HUS mice with no regeneration processes. In addition, VEGF-positive cells were frequently found in the endothelial cell region of vesicle walls, and were detected in all phases of renal injury and recovery. This indicates that VEGF may play an important role in the early and delayed renal injury recovery processes.

Furthermore, angiopoietins constitute a family of secreted growth factors that predominantly target endothelia. Ang-1 binds to and phosphorylates the Tie-2 receptor, with context-dependent effects including enhancement of endothelial cell survival, and capillary stabilization and sprouting $[10,11]$. Mice engineered to overexpress Ang-1 in the skin have more complex and larger vessels in that tissue, whereas Ang-1-null mutant mice have defective endocardial differentiation and failure of embryonic vascular remodeling [10]. Ang-1 and Tie-2 are expressed from the embryonic inception of the mammalian kidney, with transcript levels peaking perinatally; they are present at lower levels in adulthood. Ang-1 is expressed in metanephric mesenchymal cells, diverse developing tubules, and mature podocytes [11]. Long et al. [12] found increased Ang-1 expression in folic acid-induced nephrotoxicity in mice, and that Ang-1 therapy enhances fibrosis and inflammation. As to the relationship between VEGF and Ang-1, VEGF and Ang-1 appear to have a complementary role in the formation of both the blood vessel and lymphatic vessels. The VEGF system appears to play a key role in vessel sprouting and new vessel initiation, whereas Ang-1 plays a role in the remodeling/ maturation phases [21]. Takazawa et al. [22] observed accelerated repair of glomerular endothelium accompanied by renal induction of VEGF-A signal and increase in the 
Ang-1:Ang-2 ratio in the early phase of anti-Thy-1.1 nephritis.

In our study, greater glomerular Ang-1 expression was found in mild HUS model mice undergoing the regeneration processes than in typical HUS mice with no regeneration processes. In addition, Ang-1 expression was frequently found in the endothelial cell region of vesicle walls simultaneous with increased CD31-positive staining. Thus, Ang-1 may be associated with the regeneration processes of endothelial cells. In the severe HUS model mice, no Ang-1 expression in the glomeruli was found, although VEGF expression in the glomeruli did appear, resulting in an absence of renal injury recovery. These results suggest that the presence of Ang-1, together with VEGF, may be necessary for the recovery process of renal injury. Furthermore, to prove the detailed mechanisms of Ang-1 and VEGF in renal injury, it is necessary to investigate the efficacy of administration of Ang-1, Ang-2 and VEGF in a mice model of renal injury.

In conclusion, HUS mice treated with low dose of LPS and Stx 2 afforded an adequate model for the study of the recovery process from acute renal injury, and VEGF and Ang-1 were shown to play important roles in this recovery process, particularly in the regeneration of endothelial injury.

\section{Disclosure Statement}

None.

\section{References}

1 Karmali MA, Petric M, Lim C, Fleming DC, Arthus GS, Lior H: The association between idiopathic hemolytic uremic syndrome and infection by verotoxin-producing Escherichia coli. J Infect Dis 1985;151:775-782.

-2 Keir L, Coward RJ: Advances in our understanding of the pathogenesis of glomerular thrombotic microangiopathy. Pediatr $\mathrm{Ne}$ phrol 2011;26:523-533.

-3 Karpman D, Sartz L, Johnson S: Pathophysiology of typical hemolytic uremic syndrome. Semin Thromb Hemost 2010;36:575-585.

-4 Scheiring J, Andreoli SP, Zimmerhackl LB: Treatment and outcome of Shiga-toxin-associated hemolytic uremic syndrome (HUS). Pediatr Nephrol 2008;23:1749-1760.

5 Kitamoto Y, Tokunaga H, Tomita K: Vascular endothelial growth factor is an essential molecule for mouse kidney development: glomerulogenesis and nephrogenesis. J Clin Invest 1997:99:2351-2357.

-6 Eremina V, Sood M, Haigh J, Nagy A, Lajoie G, Ferrara N, Gether HP, Kikkawa Y, Miner JH, Quaggin SE: Glomerular specific alterations of VEGF-A expression lead to distinct congenital and acquired renal diseases. J Clin Invest 2003;111:707-716.

-7 Ostendorf T, Kunter U, Eitner F, Loos A, Regele $\mathrm{H}$, Kerjaschki D, Henninger DD, Janjic N, Floege J: VEGF(165) mediates glomerular endothelial repair. J Clin Invest 1999;104: 913-923.

-8 Haas CS, Câmpean V, Kuhlmann A, Dimmler A, Reulbach U, Forster C, Aigner T, Acker T, Plate K, Amann K: Analysis of glomerular VEGF mRNA and protein expression in murine mesangioproliferative glomerulonephritis. Virchows Arch 2007;450:81-92.
$\$ 9$ Gale NW, Thurston G, Davis S, Wiegand SJ, Holash J, Rudge JS, Yancopoulos GD: Complementary and coordinated roles of the VEGFs and angiopoietins during normal and pathologic vascular formation. Cold Spring Harb Symp Quant Biol 2002;67:267273.

10 Suri C, McClain J, Thurston G, McDonald DM, Zhou H, Oldmixon EH, Sato TN, Yancopoulos GD: Increased vascularization in mice overexpressing angiopoietin-1. Science 1997;282:468-471

11 Suri C, Jones PF, Patan S, Bartunkova S, Maisonpierre PC, Davis S, Sato TN, Yancopoulos GD: Requisite role of angiopoietin-1, a ligand for the TIE2 receptor, during embryonic angiogenesis. Cell 1996;87:1171-1180.

12 Long DA, Price KL, Ioffe E, Gannon CM, Gnudi L, White KE, Yancopoulos GD, Rudge JS, Woolf AS: Angiopoietin-1 therapy enhances fibrosis and inflammation following folic acid-induced acute renal injury. Kidney Int 2008;74:300-309.

13 Sugatani J, Igarashi T, Munakata M, Komiyama $\mathrm{Y}$, Takahashi $\mathrm{H}$, Komiyama N, Maeda T, Takeda T, Miwa M: Activation of coagulation in $\mathrm{C} 57 \mathrm{BL} / 6$ mice given verotoxin 2 (VT2) and the effect of co-administration of LPS with VT2. Thromb Res 2000;100:61-72.

14 Ikeda M, Ito S, Honda M: Hemolytic uremic syndrome induced by lipopolysaccharide and Shiga-like toxin. Pediatr Nephrol 2004 19:485-489.

15 Karpman D, Connel H, Svensson M, Scheutz F, Alm P, Svanborg C: The role of lipopolysaccharide and Shiga-like toxin in a mouse model of Escherichia coli O157:H7 infection. J Infect Dis 1997;175:611-620.
16 Taylor CM, Williams JM, Lote CJ, Howie AJ, Thewles A, Wood JA, Milford DV, Raafat F, Chant I, Rose PE: A laboratory model of toxin-induced hemolytic uremic syndrome. Kidney Int 1999;55:1367-1374.

17 Keepers TR, Psotka MA, Gross LK, Obrig TG: A murine model of HUS: Shiga toxin with lipopolysaccharide mimics the renal damage and physiologic response of human disease. J Am Soc Nephrol 2006;17:34043414.

18 Kawasaki Y, Tanji M, Takano K, Fukuda Y, Isome M, Nozawa R, Suzuki H, Hosoya M: The leukotriene B4 receptor antagonist ONO-4057 inhibits mesangioproliferative changes in anti-Thy-1 nephritis. Nephrol Dial Transplant 2005;20:2697-2703.

19 Kawasaki Y, Hosoya M, Isome M, Nozawa R, Suzuki H: Renal effects of Coxsackie B4 virus in hyper-IgA mice. J Am Soc Nephrol 2006;17:2760-2769.

20 Zhang L, Nakazawa K, Shigematsu H: Participation of endothelial cells and transformed mesangial cells in remodeling of glomerular capillary loops in Thy-1 nephritis. Pathol Int 2001;51:227-239.

21 Thurston G: Role of angiopoietins and Tie receptor tyrosine kinases in angiogenesis and lymphangiogenesis. Cell Tissue Res 2003;314:61-68.

-22 Takazawa Y, Maeshima Y, Kitayama H, Yamamoto Y, Kawachi H, Shimizu F, Matsui $\mathrm{H}$, Sugiyama H, Yamasaki Y, Makino H: Infusion of angiotensin II reduces loss of glomerular capillary area in the early phase of anti-Thy-1.1 nephritis possibly via regulating angiogenesis-associated factors. Kidney Int 2005;68:704-722. 